\title{
Large bowel myoelectrical activity in man
}

\author{
I. TAYLOR, H. L. DUTHIE, R. SMALLWOOD, AND D. LINKENS
}

From the Departments of Surgery, Medical Physics, and Control Engineering, University of Sheffield

SUMMARY The myoelectrical activity of human colon and rectum has been studied by three types of electrode in man-intraluminal (suction), serosal and cutaneous. The patterns obtained indicate a high degree of consistency between the methods and the value of surface electrodes is emphasized.

Gradients along the large bowel of both frequency and percentage electrical activity have been observed and possible physiological roles are postulated for them. By correlating the features of regular electrical and corresponding regular motor waves an alteration in the myoelectrical pattern is observed in the region of the rectosigmoid junction.

The main electrical wave form detected in the smooth muscle of the stomach and small bowel is known as the slow wave or basic electrical rhythm and is present all the time. Slow waves are thought to coordinate gastrointestinal motility and their characteristics have been described both in vivo and in vitro (Daniel, Wachter, Honour, and Bogoch, 1960; Bass, Code, and Lambert, 1961; Duthie, Brown, Robertson-Dunn, Kwong, Whittaker, and Waterfall, 1972). The situation in the colon and rectum is more complex. In a previous study of the rectosigmoid region in man we described long periods of electrical silence, particularly in the lower sigmoid region, although in the lower rectum slow waves were more constant and regular (Taylor, Duthie, Smallwood, Brown, and Linkens, 1974). These observations agree with other work (Provenzale and Pisano, 1971). In addition two distinct rhythms of slow waves were recognized in this region: a predominant higher frequency one (6-10 $\mathrm{c} / \mathrm{m})$, and a less commonly observed lower frequency one $(2 \cdot 5-4 \mathrm{c} / \mathrm{m})$ with a greater amplitude. We have now extended these initial studies to the more proximal large bowel.

\section{Methods}

Electrical slow waves of the smooth muscle of the colon and rectum were recorded in 108 subjects with no known pathology in this area, using three types of electrodes-intraluminal, serosal and cutaneous.

Received for publication 9 July 1975
INTRALUMINAL ELECTRODES

A fine stainless steel electrode mounted on a tube was passed into the rectum and sigmoid and attached to the mucosal surface of the bowel by suction, as previously described (Taylor et al, 1974). The tube was also introduced through the stoma of left iliac fossa colostomies and into the proximal and distal limits of transverse colostomies to a distance of at least $15 \mathrm{~cm}$. Corresponding intraluminal pressure changes have been measured by means of a thin, open-ended tube placed diametrically opposite the electrode and attached to a pressure transducer.

\section{SEROSAL ELECTRODES}

Fine, stainless steel electrodes (Waterfall, Brown, Duthie, and Whittaker, 1972) were implanted under the serosal coat of the ascending colon or the transverse colon in 12 patients undergoing cholecystectomy. In two patients the electrodes were placed at the same level on the taenia coli and circular muscle. The wires from the electrodes were led out with the surgical drain and were removed together on the fifth postoperative day. Twelve recordings were obtained from the right colon and 14 recordings from the transverse colon.

\section{CUTANEOUS ELECTRODES}

Two silver/silver chloride electrodes similar to the type used for electrocardiography were placed $5 \mathrm{~cm}$ apart on the skin overlying the ascending or descending colon (fig 1). Evidence for the colon as the sole source of the signals obtained from cutaneous electrodes stems from the following observations:-

(a) Under radiological control an intraluminal electrode was passed via a left iliac fossa colostomy 


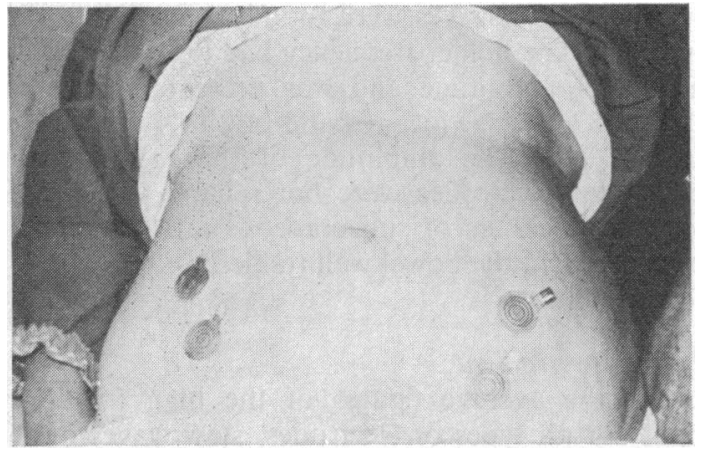

Fig 1 Position of cutaneous electrodes on abdominal wall overlying ascending and descending colon

into the descending colon to lie directly under the cutaneous electrode. The recordings from the two types of electrodes had identical frequencies and were in phase suggesting, an origin from the same source (fig 2). Also the frequencies of rhythms obtained from serosal and cutaneous electrodes over the right colon were identical.

(b) The regular wave form obtained from cutaneous electrodes over the colon was no longer observed following total colectomy (for ulcerative colitis) (fig 3).

The signals obtained from the three types of electrodes were similarly amplified (AC amplifier with a frequency response $\pm 3 \mathrm{bB}$ of $0.02 \mathrm{~Hz}$ to $1 \mathrm{KHz}$ ) and fed into an ultra-violet recorder for visual analysis. A parallel output was recorded on magnetic tape and fast Fourier transform computer analyses of stretches of the data were performed to show the main frequencies of the slow wave. The time during which regular slow wave activity to both the higher and lower frequency band was present was expressed as a percentage of the total recording time (percentage electrical activity).

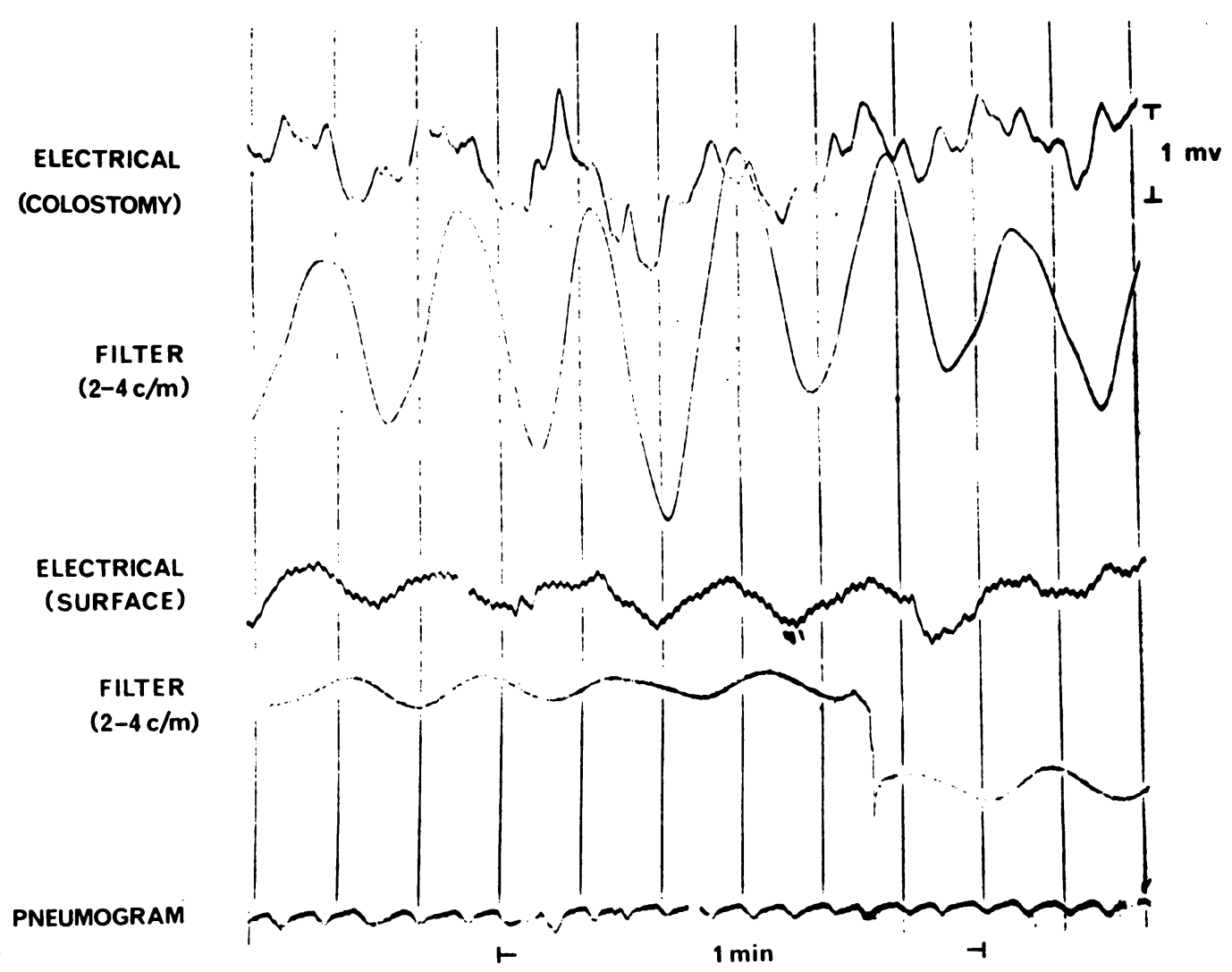

Fig 2 The $3 \mathrm{c} / \mathrm{m}$ rhythm obtained by an intraluminal electrode from the descending colon (top trace) has the same frequency as the rhythm obtained by a cutaneous electrode (bottom trace) and is to be seen in phase, indicating an origin from the same source. A filtered version of each recording is included. 
DES.
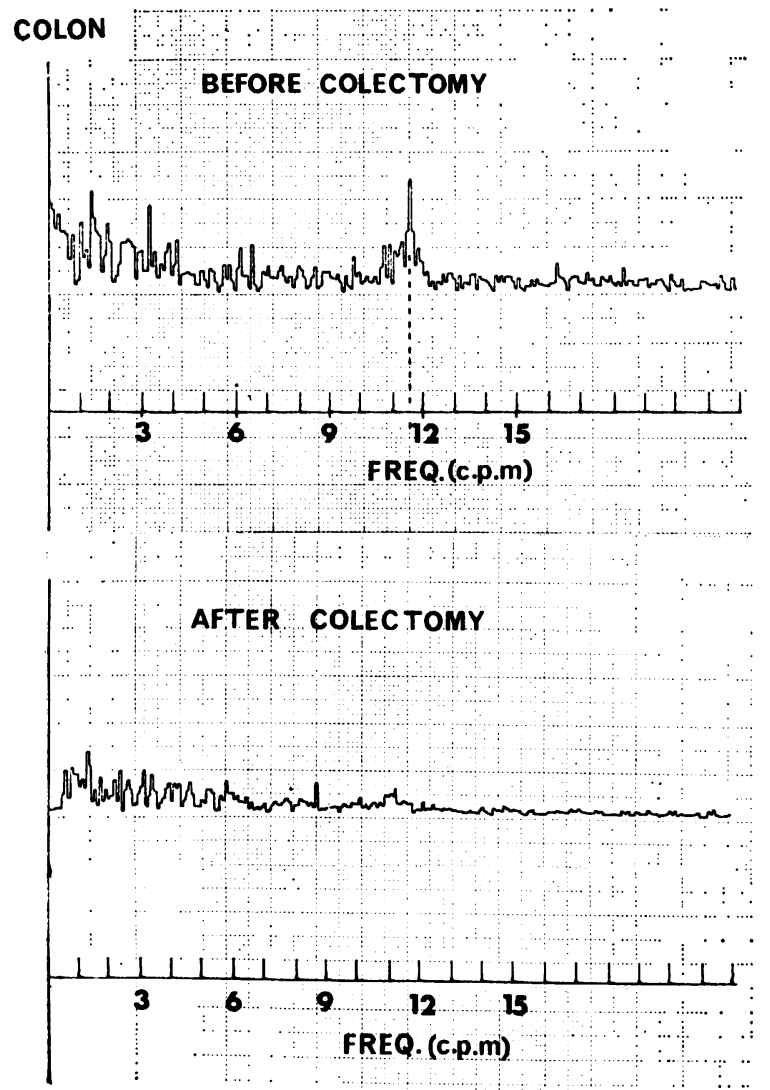

Fig 3 A frequency analysis of a stretch of data obtained by cutaneous electrodes before and after colectomy in the same subject. Note the disappearance of the higher frequency band.

\section{Results}

ELECTRICAL

Slow wave frequency

Using all three types of electrode, two frequency bands of slow waves were found around the colon (table I). The higher frequency band $(6-11 \mathrm{c} / \mathrm{m})$ had a smaller amplitude and was present more often than the lo ver frequency band of 2 to $4 \mathrm{c} / \mathrm{m}$ (tables II and III). The amplitude of the records from cutaneous electrodes were not reliable due to the varying thickness of subcutaneous fat between the electrode and the bowel wall (table IV).

\section{Frequency gradient}

Using the average figures of the high frequency band for all types of electrodes, slow waves of the right colon were faster than in the transverse colon and almost the same as in the descending colon. In individual subjects a faster higher frequency band was obtained from the descending colon by cutaneous electrodes than from the rectum by intraluminal electrodes (fig 4). Through the sigmoid and upper rectum a clear, defined gradient was formed from $9.2 \mathrm{c} / \mathrm{m}$ in the lower sigmoid to $7 \cdot 1 \mathrm{c} / \mathrm{m}$ at 5 to $9 \mathrm{~cm}$ from the anus (fig 5). Short plateaux of frequency have been observed and confirmed by cross-correlation techniques in individuals from all areas but these plateaux are unstable. The lower frequency slow waves of approximately $3 \mathrm{c} / \mathrm{m}$ showed no gradient and short plateaux could be found by cross-correlation techniques both in the right colon and rectum.

\section{Gradient of percentage activity}

The total electrical activity recorded varied along the colon as did the proportion of time occupied by each of the two frequency bands noted above. The percentage electrical activity also showed gradients in the colon with peaks in the ascending colon and rectum and a lower percentage activity between (fig 6). The lower frequency band has a peak incidence in the caecum and rectum and a steady incidence between these points. The greater incidence of the lower frequency band chiefly contributed to the peak percentage electrical activity in these areas.

\begin{tabular}{|c|c|c|c|}
\hline & \multicolumn{2}{|c|}{ Frequency $(c / m)$} & \multirow[t]{2}{*}{ Percentage Electrical Activity } \\
\hline & High & Low & \\
\hline $\begin{array}{l}\text { Right colon } \\
\text { Transverse colon } \\
\text { Descending colon } \\
\text { Lower sigmoid }\end{array}$ & $\begin{array}{r}10.6 \pm 0.2 \\
9.6 \pm 0.3 \\
10.7 \pm 0.1\end{array}$ & $\begin{array}{l}3.04 \pm 0.03 \\
3 \cdot 1 \pm 0 \cdot 08 \\
3 \cdot 2 \pm 0 \cdot 1\end{array}$ & $\begin{array}{l}70 \cdot 5 \pm 7.4 \\
69 \cdot 1 \pm 8 \cdot 7 \\
36.9 \pm 3.9\end{array}$ \\
\hline $\begin{array}{c}>25 \mathrm{~cm} \\
20-24 \mathrm{~cm} \\
\text { Rectum }\end{array}$ & $\begin{array}{l}9 \cdot 2 \pm 0.3 \\
7.9 \pm 0.2\end{array}$ & $\begin{array}{l}2.9 \pm 0 \cdot 1 \\
3 \cdot 2 \pm 0.01\end{array}$ & $\begin{array}{l}26 \cdot 1 \pm 3 \cdot 1 \\
27 \cdot 3 \pm 2 \cdot 5\end{array}$ \\
\hline $\begin{array}{l}15-19 \mathrm{~cm} \\
10-14 \mathrm{~cm} \\
5-9 \mathrm{~cm}\end{array}$ & $\begin{array}{l}7 \cdot 5 \pm 0 \cdot 1 \\
7 \cdot 2 \pm 0 \cdot 1 \\
7 \cdot 1 \pm 0 \cdot 1\end{array}$ & $\begin{array}{l}3 \cdot 2 \pm 0 \cdot 1 \\
3 \cdot 4 \pm 0 \cdot 1 \\
3 \cdot 2 \pm 0 \cdot 1\end{array}$ & $\begin{array}{l}31 \cdot 2 \pm 2.9 \\
34 \cdot 3 \pm 2 \cdot 5 \\
71 \cdot 4 \pm 4 \cdot 5\end{array}$ \\
\hline
\end{tabular}

Table I Mean frequency and percentage electrical activity at all levels in the large bowel (mean $\pm 1 S E M)$ 


\begin{tabular}{|c|c|c|c|c|c|c|c|}
\hline & \multicolumn{2}{|l|}{ Frequency $(c / m)$} & \multicolumn{2}{|c|}{ Amplitude $(m V)$} & \multicolumn{3}{|c|}{ Percentage Incidence } \\
\hline & High & Low & High & Low & High & Low & Total (PEA) \\
\hline $\begin{array}{l}\text { Ascending colon } \\
\text { Transverse }\end{array}$ & $\begin{array}{l}11.8 \pm 0.1(4)^{1} \\
10.2(3)\end{array}$ & $3.1 \pm 0.09(2 / 4)$ & $0.4 \pm 0.06$ & $0.6 \pm 0.07$ & $34 \cdot 1 \pm 10 \cdot 7$ & $15 \cdot 0 \pm 3 \cdot 0$ & $40 \cdot 8 \pm 9 \cdot 7$ \\
\hline $\begin{array}{l}\text { Descending } \\
\text { Rectosigmoid } \\
\text { (cm from anus) }\end{array}$ & $\begin{array}{l}10.5 \pm 0.3(10) \\
10.8 \pm 0.05\end{array}$ & $\begin{array}{l}3 \cdot 4(3 / 10) \\
3 \cdot 6(2 / 10)\end{array}$ & $\begin{array}{l}0.5 \pm 0.04 \\
0.5 \pm 0.1\end{array}$ & $\begin{array}{l}0.9 \\
0.8\end{array}$ & $\begin{array}{l}26 \cdot 1 \pm 2 \cdot 6 \\
16 \cdot 9 \pm 4 \cdot 1\end{array}$ & & \\
\hline $\begin{array}{l}>25 \\
20-24 \\
15-19 \\
10-14 \\
5-9\end{array}$ & $\begin{array}{l}7.1 \pm 0.1(33) \\
7.2 \pm 0.1(26) \\
7.5 \pm 01(20) \\
7.9 \pm 0.2(24) \\
9.2 \pm 0.3(13)\end{array}$ & $\begin{array}{l}3.2 \pm 0.1(13 / 33) \\
3.4 \pm 0.1(14 / 26) \\
3.2 \pm 0.1(9 / 20) \\
3.2 \pm 0.01(8 / 24) \\
2.9 \pm 0.15(4 / 13)\end{array}$ & $\begin{array}{l}0.5 \pm 0.01 \\
0.5 \pm 0.03 \\
0.5 \pm 0.03 \\
0.4 \pm 0.03 \\
0.4 \pm 0.04\end{array}$ & $\begin{array}{l}1.0 \pm 0.01 \\
0.8 \pm 0.09 \\
1.0 \pm 0.03 \\
0.7 \pm 0.06 \\
0.9 \pm 0.05\end{array}$ & $\begin{array}{l}50 \cdot 6 \pm 4 \cdot 3 \\
21 \cdot 3 \pm 2 \cdot 2 \\
22 \cdot 5 \pm 2 \cdot 4 \\
21 \cdot 2 \pm 2 \cdot 3 \\
20 \cdot 7 \pm 2 \cdot 9\end{array}$ & $\begin{array}{c}20.2 \pm 5.5 \\
12.6 \pm 3.0 \\
7.5 \pm 2.6 \\
6.1 \pm 2.4 \\
3.7 \pm 2.05\end{array}$ & $\begin{array}{l}26 \cdot 1 \pm 3 \cdot 1 \\
27 \cdot 3 \pm 2 \cdot 5 \\
31 \cdot 2 \pm 2 \cdot 1 \\
34 \cdot 3 \pm 2 \cdot 5 \\
71 \cdot 4 \pm 4 \cdot 5\end{array}$ \\
\hline
\end{tabular}

Table II Electrical characteristics obtained with intraluminal electrodes ( 1 I SEM)

${ }^{1}()=$ number of subjects tested

\begin{tabular}{|c|c|c|c|c|c|c|c|}
\hline \multirow[t]{2}{*}{ Colon } & \multicolumn{2}{|c|}{ Frequency $(\mathrm{c} / \mathrm{m})$} & \multicolumn{2}{|c|}{ Amplitude $(m V)$} & \multicolumn{2}{|c|}{ Percentage Incidence } & \multirow[t]{2}{*}{ Total (PEA) } \\
\hline & Fast & Slow & Fast & Slow & Fast & Slow & \\
\hline \multicolumn{8}{|l|}{ Ascending (12) } \\
\hline $\begin{array}{c}\text { Caecum } \\
\mathrm{AC}_{\mathbf{1}} \\
\mathrm{AC}_{\mathbf{2}} \\
\mathrm{AC}_{\mathbf{8}} \\
\text { Transverse (14) }\end{array}$ & $\begin{array}{l}10.0 \pm 0.15 \\
10.7 \pm 0.18 \\
10.8 \pm 0.13 \\
10.0 \pm 0.4\end{array}$ & $\begin{array}{l}2.9 \pm 0.3 \\
3.1 \pm 0.08 \\
3.0 \pm 0.1 \\
3.2 \pm 0.06\end{array}$ & $\begin{array}{l}0.3 \pm 0.05 \\
0.6 \pm 0.06 \\
0.4 \pm 0.04 \\
0.4 \pm 0.01\end{array}$ & $\begin{array}{l}0.6 \pm 0.1 \\
0.8 \pm 0.1 \\
0.7 \pm 0.12 \\
0.8 \pm 0.15\end{array}$ & $\begin{array}{l}50.4 \pm 12.5 \\
80.4 \pm 8.1 \\
73.1 \pm 7.2 \\
71.4 \pm 3.8\end{array}$ & $\begin{array}{r}21.4 \pm 3.2 \\
5.0 \pm 1.3 \\
5.2 \pm 0.8 \\
4.0 \pm 0.5\end{array}$ & $\begin{array}{l}70 \cdot 9 \pm 8 \cdot 6 \\
82 \cdot 6 \pm 5 \cdot 2 \\
77 \cdot 8 \pm 4 \cdot 1 \\
74 \cdot 2 \pm 2 \cdot 8\end{array}$ \\
\hline $\begin{array}{l}\mathbf{E A _ { 1 }} \\
\mathbf{E A _ { 2 }} \\
\mathbf{E A _ { 3 }} \\
\mathbf{E A _ { 4 }}\end{array}$ & $\begin{array}{l}9.8 \pm 0.2 \\
9.5 \pm 0.19 \\
9.8 \pm 0.2 \\
9.8 \pm 0.16\end{array}$ & $\begin{array}{l}3.0 \pm 0.08 \\
3.0 \pm 0.06 \\
3.3 \pm 0.05 \\
3.3 \pm 0.25\end{array}$ & $\begin{array}{l}0.5 \pm 0.02 \\
0.5 \pm 0.02 \\
0.5 \pm 0.04 \\
0.6 \pm 0.02\end{array}$ & $\begin{array}{l}1.1 \pm 0.5 \\
0.8 \pm 0.2 \\
0.8 \pm 0.1 \\
0.8 \pm 0.2\end{array}$ & $\begin{array}{l}47 \cdot 5 \pm 8 \cdot 1 \\
63 \cdot 3 \pm 11 \cdot 9 \\
69 \cdot 3 \pm 10 \cdot 7 \\
62.1 \pm 10.3\end{array}$ & $\begin{array}{r}10 \cdot 8 \pm 6.2 \\
9 \cdot 1 \pm 5 \cdot 2 \\
3 \cdot 3 \pm 2.1 \\
8.7 \pm 3.6\end{array}$ & $\begin{array}{l}62.5 \pm 4.1 \\
80.5 \pm 9.6 \\
70.5 \pm 8.6 \\
66.4 \pm 6.7\end{array}$ \\
\hline
\end{tabular}

Table III Electrical characteristics obtained with serosal electrodes ( 1 I SEM)

\begin{tabular}{llllll}
\hline & Frequency $(c / m)$ & \multicolumn{2}{l}{ Percentage Incidence } & & Total $(P E A)$ \\
\hline Ascending (23 patients) & $10.2 \pm 0.2$ & $3.4 \pm 0.4(13)$ & $78.7 \pm 6.9$ & $8.2 \pm 4.7$ & $82.6 \pm 5.8$ \\
Descending (16 patients) & $10.8 \pm 0.1$ & $3.1 \pm 0.01(4)$ & $37.6 \pm 9.3$ & $2.5 \pm 1.8$ & $39.8 \pm 5.7$ \\
\hline
\end{tabular}

Table IV Electrical characteristics obtained with cutaneous electrodes ( 1 SEM)

SURFACE

ASC. COLON

INTRALUMINAL

RECTUM $(15 \mathrm{~cm})$

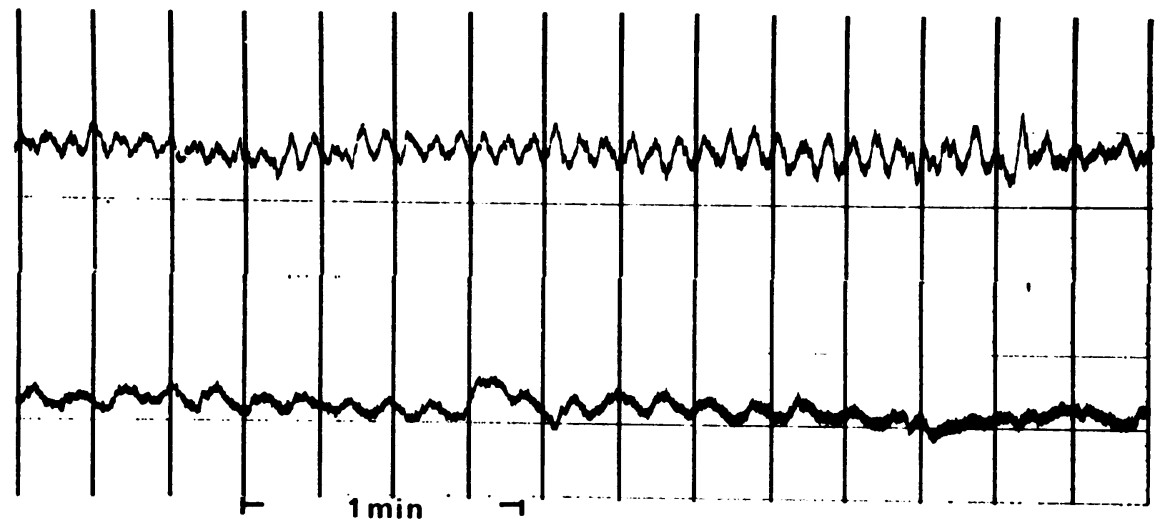

Fig 4 An illustration of the higher frequency band obtained simultaneously by cutaneous electrodes from the ascending colon $(10.8 \mathrm{c} / \mathrm{m})$ and by an intraluminal electrode from the rectum $(6.6 \mathrm{c} / \mathrm{m})$ 


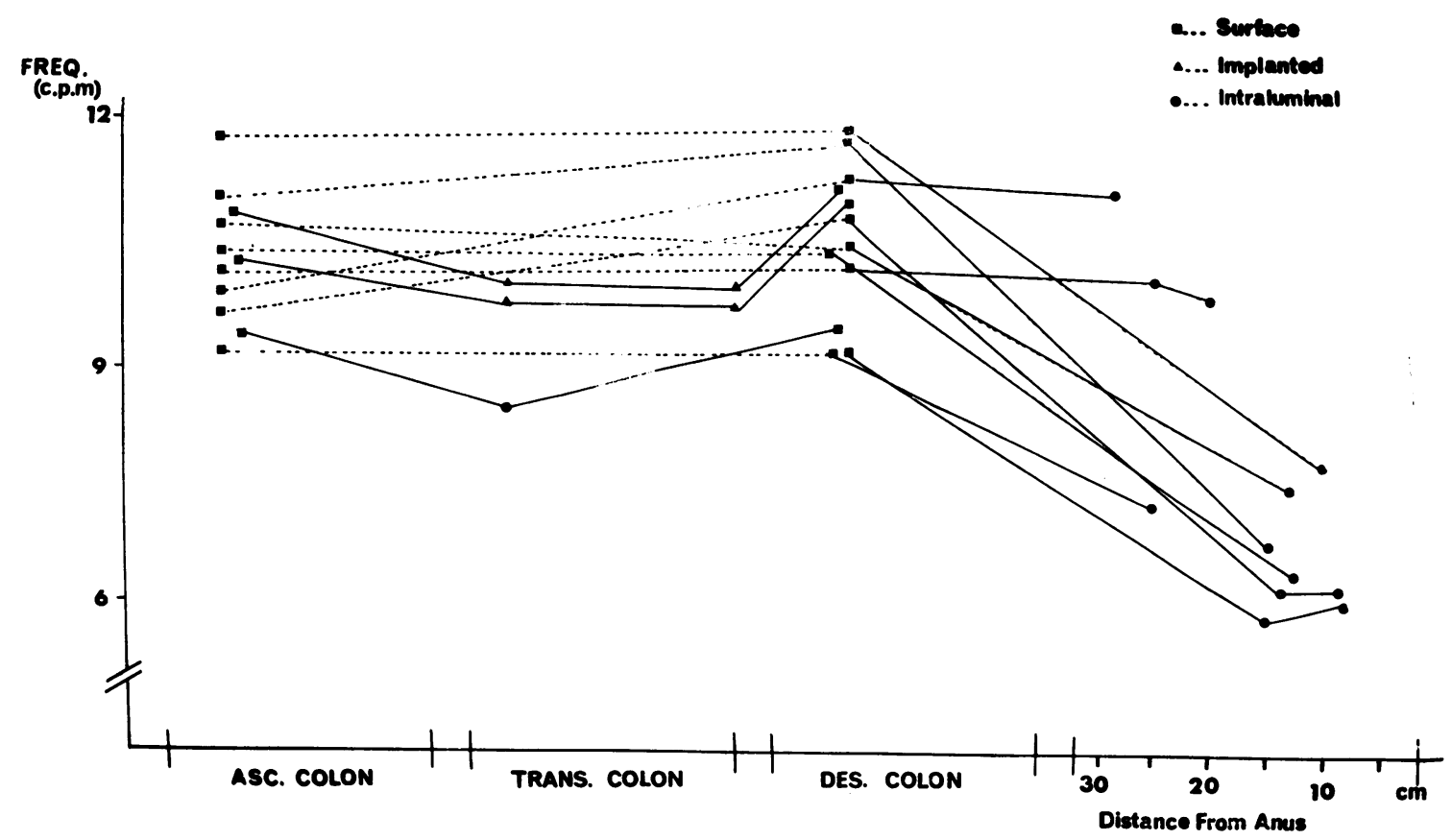

Fig 5 The mean value of the higher frequency band throughout the large bowel and rectum. Note the tendency for a frequency gradient of slow waves in the distal part.

\section{PRESSURE}

Regular sequences of pressure waves in all regions occurred with a frequency corresponding to the slow wave frequency. Thus a $6 /$ minute run of pressure waves corresponded to the faster band of slow wave activity and the $3 /$ minute pressure waves were coupled to the slower band. Single pressure

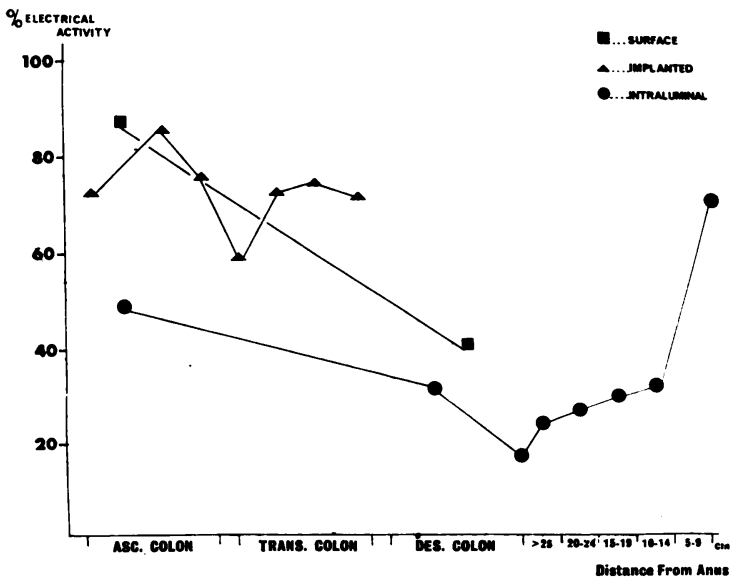

Fig 6 The percentage electrical activity obtained by all three methods throughout the large bowel and rectum. waves were recorded at any time and were not restricted to one or other of the electrical rhythms. The greatest proportion of the percentage motility was composed of $3 /$ minute pressure waves at all levels other than around $20 \mathrm{~cm}$ from the anus (fig 7). At this level a higher percentage of irregular pressure waves was observed.

No regular pressure activity was present during the periods of zero electrical activity. Only infrequently were distinct action potentials recognized in relation to regular pressure waves.

\section{Discussion}

The pattern of the electrical activity of the smooth muscle of the colon is more complex than that of the stomach and small bowel due to the fact that more than one frequency of slow waves can be recorded from one site (Taylor et al, 1974). The lower frequency band displays a similar frequency at all levels of the large bowel when present with no apparent gradient of activity. The higher frequency band varies along the bowel and is far more commonly observed than the slower. There is little change in frequency from the right colon along the transverse but a definite gradient exists from the sigmoid down into the rectum. Similar trends have 


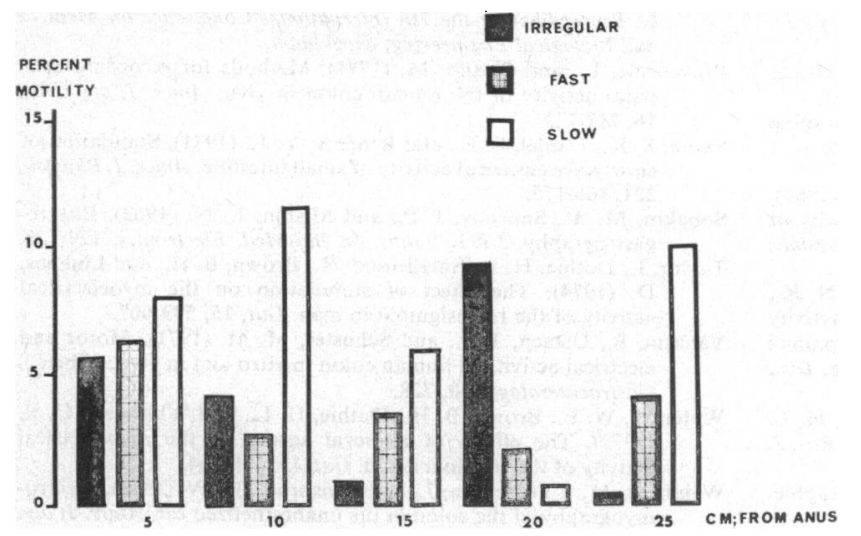

Fig 7 The mean percentage motility obtained from the rectosigmoid. The main component consists of regular $3 / \mathrm{min}$ pressure waves (corresponding to the slower frequency electrical band) at all levels other than around $20 \mathrm{~cm}$ from the anus where irregular waves predominate.

been noted in the cat colon in vivo (Weinbeck, Christensen, and Weisbrodt, 1972). In vitro, however, the cat colon shows a frequency gradient towards the caecum (Christensen, Anuras, and Hauser, 1974). Vanasin, Ustach, and Schuster (1971) have also speculated on the existence of two gradients within the human large bowel. In most studies a common factor appears to be a change in the frequency characteristics in the region of the splenic flexure. It is tempting to postulate that this is related to the embryological change from mid to hind gut which occurs in this area.

These gradients in slow wave frequency may be related to differences in transit on different sides of the colon. A shallow frequency gradient on the right would suggest less propulsive movement and would allow frequency changes in position of the faeces permitting maximum exposure for absorption. On the left the steep gradient to the lower rectum may be associated with more rapid movement to the rectum until ready for evacuation.

The gradient of activity, which may have more correlation with the functions of the colon, is that of the percentage activity. In this we find that the highest points are in the caecum and the rectum. These peaks are due to a large increase in the incidence of the $3 \mathrm{c} / \mathrm{m}$ rhythm. We have shown that this rhythm is resistant to the influence of neostigmine and bisacodyl (Taylor et al, 1974). It may be that it provides the electrical basis for controlled slowing of transit in the caecum and rectum whereas the slow wave in the higher frequency band subserves more rapid transport of luminal contents.

There appears to be a clear association between the regular pressure waves and slow wave frequency. The $3 /$ minute pressure activity occupies a higher proportion of regular wave activity at all levels other than in the region of the rectosigmoid. Whether this is associated with an alteration in function or transit at this level (the recto-sigmoid 'sphincter') is problematical at present.

Of the recording techniques described, the one which is clearly the most controversial is the cutaneous electrode. Nevertheless its overall success rate approaches that of intraluminal recordings. Only the frequency and regularity of the colonic wave forms can be determined by this method, unlike an electrocardiograph where alterations in wave form can be recognized and have diagnostic value. However, the technique involves no trauma or discomfort for the patient and can be used before operation but chiefly to record the gastric slow waves (Sobakin, Smirnov, and Mishin, 1962; Nelsen, 1967; Kwong, Brown, Whittaker, and Duthie, 1970). Martin and Thillier (1971) have attempted to define electrical axes, similar to ECG work, for both colon and stomach. Technical problems in recording have hindered progress in this field but surface recordings may well prove subsequently to have diagnostic as well as research potential.

When recordings from taenia and intraluminal areas obtained by implanted electrodes in this study were compared, no significant differences could be detected. This is contrary to the results of Provenzale and Pisano (1970), who were able to demonstrate more regular slow waves from the intertaenial areas, although with no differences in the slow wave frequency. It appears that all smooth muscle fibres from a particular area of the bowel have definite frequency characteristics which are constant whatever their anatomical arrangements. This would be particularly so if the fibres are considered to be arranged in the form of a matrix as postulated by the relaxation oscillator theory (Sarna, Daniel, and Kingma, 1971). 
References

Bass, P., Code, C. F., and Lambert, E. H. (1961). Motor and electrical activity of the duodenum. Amer. J. Physiol., 201, 287-291.

Christensen, J., Anuras, S., and Hauser, R. L. (1974). Migrating spike bursts and electrical slow waves in the cat colon: effect of sectioning. Gastroenterology, 66, 240-247.

Daniel, E. E., Wachter, B. T., Honour, A. J., and Bogoch, A. (1960), The relationship between electrical and mechanical activity of the small intestine of dog and man. Canad. J. Biochem. Physiol., 38, 777-791.

Duthie, H. L., Brown, B. H., Robertson-Dunn, B., Kwong, N. K., Whittaker, G. E., and Waterfall, W. (1972). Electrical activity in the gastro-duodenal area-slow waves in the proximal duodenum: a comparison of man and dog. Amer.J. dig. Dis., 17, 344-351.

Kwong, N. K., Brown, B. H., Whittaker, G. E., and Duthie, H. L. (1970). Electrical activity of the gastric antrum in man. Brit. $J$. Surg., 57, 913-916.

Martin, A., and Thillier, J. (1971). L'électro-gastro-enterographie. Presse med., 79, 1235-1237.

Nelsen, T. S. (1967). Use of phaselock techniques for retrieval of the electrogastrogram from cutaneous and swallowed electrodes.
In Proceedings of the 7th International Conference on Medical and Biological Engineering, Stockholm.

Provenzale, L., and Pisano, M. (1971). Methods for recording electrical activity of the human colon in vivo. Amer. J. dig. Dis., 16, 712-722.

Sarna, S. K., Daniel, E. E., and Kingma, Y. J.. (1971). Simulation of slow-wave electrical activity of small intestine. Amer.J. Physiol., 221, 166-175.

Sobakin, M. A., Smirnov, I. P., and Mishin, L. N. (1962). Electrogastrography. I.R.E. Trans. on Bio-Med. Electronics, 129-132.

Taylor, I., Duthie, H. L., Smallwood, R., Brown, B. H., and Linkens, D. (1974). The effect of stimulation on the myoelectrical activity of the rectosigmoid in man. Gut, 15, 599-607.

Vanasin, B., Ustach, T. J., and Schuster, M. M. (1971). Motor and electrical activity in human colon in vitro and in vivo. (Abstr.). Gastroenterology, 60, 728.

Waterfall, W. E., Brown, B. H., Duthie, H. L., and Whittaker, G. E. (1972). The effects of humoral agents on the myoelectrical activity of the terminal ileum. Gut, 13, 528-534.

Weinbeck, M., Christensen, J., and Weisbrodt, N. W. (1972). Electromyography of the colon in the unanesthetized cat. Amer. J. dig. Dis., 17, 356-362. 